\title{
TESL Trainee Practitioners' Self Perception of their Personality Traits and Verbal Communication Skills
}

\author{
Abdul Rashid Abdul Sitra \\ SMK Taman Medan, KM 12, Jalan Klang Lama, 46100 Petaling, Selangor, Malaysia \\ E-mail: guptgupt75@gmail.com
}

Ain Nadzimah Abdullah (Corresponding author)

Department of English, Faculty of Modern Languages and Communication, Universiti Putra Malaysia, 43400 Serdang, Selangor, Malaysia E-mail: ain@upm.edu.my

\author{
Received: 17-03-2017 \\ Accepted: 12-05-2017 \\ Advance Access Published: September 2017 \\ Published: 01-11-2017 \\ doi:10.7575/aiac.ijalel.v.6n.6p.9 \\ URL: http://dx.doi.org/10.7575/aiac.ijalel.v.6n.6p.9
}

\begin{abstract}
The teaching and learning of English as a second language involve many different skills. This study investigates the relationship between Teaching English as a Second Language (TESL) trainee practitioners' (TPs) personality traits and their verbal communication skills. The personality traits investigated are the Big Five, while the verbal communication skills investigated include interpersonal skills, verbal-linguistic skills, motivation, altruism, and self-regulation. This study involved 277 TESL TPs from four different teacher training institutes in Malaysia. This quantitative study used questionnaires to investigate both the variables. The findings show that out of the Big Five personality traits, only openness showed positive relationship to verbal communication. This trait deserves greater attention if students are to maximise the use of effective communication skills. This study profiles personality traits to examine the relationship of each trait in relation to communication skills. The findings of this study would be significant for the Higher Education Ministry of Malaysia and education regulators, apart from the teaching community.
\end{abstract}

Keywords: Verbal Communication Skills; Personality Traits; Trainee Practitioners; TESL Programme

\section{Introduction}

Today, good English communication skills are of paramount importance in a globalised world. Hence, ESL teachers in Malaysia should have the relevant proficiency and skills to teach the English language effectively in schools and colleges. However, this is not so. In order to rectify this situation, the government has embarked on a policy to recruit English language teachers from English speaking countries on a contract basis. Thus, Malaysian ESL teachers need to improve their proficiency and teaching skills so that the teaching and learning of English in schools and colleges can be improved.

Meiking (2015) reported that the Malaysian Employers Federation (MEF) viewed the lack of good English language and communication skills to be an obstacle blocking fresh graduates from obtaining jobs. Sim (2016) also reported that a survey by an online employment agency JobStreet.com found that lack of proficiency in the English language, poor communication skills and poor personality traits were among the top five reasons for graduates' failure to find employment in Malaysia. Hairi, Nazuir and Razally (2011) found that local graduates in Malaysia were not able to find jobs in local and multinational companies because of their lack of soft skills such as communication skills. Although the teaching profession does not operate in a 'free' market scenario as the other professions, the intake and final placement of teacher trainees are very much controlled according to projected needs in schools. Communication skills are still an issue as teachers are also expected to have good communication skills in order to be effective educators. In addition, they should also have the appropriate personality traits that befit the profession. Given the importance of these skills and traits, this study attempts to investigate the connection between the two sets of broad variables to understand the related operational phenomenon.

Having soft skills, including communication skills, would mean that graduates must be able to work comfortably with people from other culture, solve problems creatively, write and speak well, think in a multidisciplinary manner, and evaluate information critically (Gewertz, 2007). Educational institutions play an integral role in preparing graduates for professional careers and in discharging their responsibilities effectively through the teaching of communication skills. These institutions include teacher training institutes which are responsible for producing effective teachers. Generally, many Malaysian Trainee Practitioners (henceforth, TPs), especially those involved in the Teaching of English as a Second Language (henceforth, TESL), face problems in communicating effectively in the English Language as English is not their mother tongue. 
Likewise, appropriate personality traits are imperative for communication to be successful in the teaching and learning context. Fatemi, Ganjal and Kafi (2016) in their research on Iranian teachers found that personality traits influenced the teachers' communication. A teacher's job, in fact, is very complex as it involves more than mere teaching. Having the requisite soft skills, such as good communication skills, is a must for teachers (Barrick \& Mount, 1991).

The Ministry of Education (MOE) and the Ministry of Higher Education (MoHE) in Malaysia are responsible for nurturing future teachers. The teacher training institutes are under the umbrella of the MOE, while universities which have education faculties are under the purview of the MoHE. However, both these ministries have the same aim, which is to produce quality teachers. Therefore, the selection process for teacher training institutes employed by both the ministries is somewhat similar and stringent.

The TPs in this study were the first batch of students enrolled in a new TESL programme and were being trained under the Bachelor of Teaching English - TESL programme. In order for these participants to enroll in this programme, they should be in possession of the School Leaving Certificate with at least an A2 grade in their English Language paper. In addition, they should have performed well overall. Beginning from 2013, anyone who intends to enrol in this programme should have obtained at least 7As out of 10 subjects (including English). This is to give greater importance to the teaching profession. However, during interviews, these aspiring teachers are not given any personality traits' tests as this has never been a requirement, even though both, the right personality traits and communication skills are important factors in successful teaching.

Since the selected trainees do not undergo a personality test, they are often left on their own to gauge their personality traits. It could be surmised that the trainees are quite unaware of their own personalities, let alone the connection between communication skills and personality traits. Having insights into the related elements will enable teachers or educators to understand the links and lead them into modifying their behaviour or communication skills where necessary, to suit the communicative event in the educational environment. According to Hamacheck (1985), there is probably no other profession where one's personality traits are as important a factor as in teaching since they contribute significantly to creating the interpersonal medium within which learning occurs.

Thus, it is generally perceived that teachers' personality traits influence students' learning, which in turn could affect communication skills as they form the channel through which learning is imparted to students. Personality traits, without doubt, affect teachers' mode of teaching and the approaches they take to interact with their students in the classroom. Davis (2005) concludes that commitment, compassion, and positive attitudes (part and parcel of personality traits) of teachers affect students' learning and their achievement. Preliminary studies in the field of teaching have found associations between teachers' beliefs and attitudes and their effectiveness in their interactions with students (Howes, Burchinal, Pianta, Bryant, Early, Clifford, \& Barbarin, 2008). Chu (2003) has also opined that personality traits affect a teacher's behaviour, attitude, and classroom management as personality is central to behaviour, attitude, and thinking. Additionally, Cloniger (2000) defines personality traits as characteristics that distinguish one person from the other and cause a person to behave more or less consistently. Keeping these postulations in mind, it is noted that, although all teachers are trained identically using similar current methods and approaches, they may not teach the same way, as their approaches could vary due to variations in individual personality traits.

A problem may arise when a teacher is unable to communicate effectively and appropriately either owing to a lack of proficiency or the teacher has been influenced by his or her personality traits. Barrick \& Mount, 1991; Joinson, 2004; Saunders \& Chester, 2008 support this view that there is also convincing evidence that communication skills are also linked to and influenced by personality traits. Teachers sometimes get into trouble with the school management when they say things that are not appropriate to their students, colleagues and sometimes even to the school administration. This problem may occur due to teachers' personality. Henson and Chambers (2002) also opine that teachers' personality traits influence their interpersonal skills. Taking this into consideration, this study looks at the relationship between TPs' personality traits and their communication skills.

\subsection{Aim of the Study}

The aim of this study is to first identify the personality traits and the level of communication skills of the TESL TPs. Thereafter, their relationships in terms of the sub traits and communication skills are explored to reveal the finer aspects of the connection.

The research question was formulated to define the scope of this study, and the hypotheses support aspects of the research question. The research question and hypotheses are as follows:

How do personality traits' correlate with the verbal communication skills of the TESL trainee practitioners?

The research question is further supported by five hypotheses. These hypotheses test the relationship between trainee practitioners' personality traits and their verbal communication skills.

Hypothesis 1

Null $\rightarrow \mathrm{H}_{0}: \beta_{1}=0$ (There is no relationship between openness and verbal communication).

Alternate $\rightarrow \mathrm{H}_{\mathrm{A}}: \beta_{1} \neq 0$ (There is a relationship between openness and verbal communication).

Hypothesis 2

Null $\rightarrow \mathrm{H}_{0}: \beta_{1}=0$ (There is no relationship between agreeableness and verbal communication). 
Alternate $\rightarrow \mathrm{H}_{\mathrm{A}}: \beta_{1} \neq 0$ (There is a relationship between agreeableness and verbal communication).

Hypothesis 3

Null $\rightarrow \mathrm{H}_{0}: \beta_{1}=0$ (There is no relationship between conscientiousness and verbal communication).

Alternate $\rightarrow \mathrm{H}_{\mathrm{A}}: \beta_{1} \neq 0$ (There is a relationship between conscientiousness and verbal communication).

Hypothesis 4

Null $\rightarrow \mathrm{H}_{0}: \beta_{1}=0$ (There is no relationship between extraversion and verbal communication).

Alternate $\rightarrow \mathrm{H}_{\mathrm{A}}: \beta_{1} \neq 0$ (There is a relationship between extraversion and verbal communication).

Hypothesis 5

Null $\rightarrow \mathrm{H}_{0}: \beta_{1}=0$ (There is no relationship between neuroticism and verbal communication).

Alternate $\rightarrow \mathrm{H}_{\mathrm{A}}: \beta_{1} \neq 0$ (There is a relationship between neuroticism and verbal communication).

\section{Literature Review}

\subsection{Verbal Communication Skills}

Norazila (2010) conceptualised communication skills as the exchange of information, facts, feelings, and emotions between individuals which results in achieving a certain objective. Successful communication occurs when the receiver perceives the meaning of the message as being similar to the intended meaning of the source. It has been said that communication and oral presentation skills of undergraduates acquired during their studies have positive effects on their later work performance (Mason, Williams, \& Cranmer, 2009).

In today's world, good communication skills are considered fundamental and essential to the workplace. Efficient and effective communication skills in everyday work situations are important when communicating with superiors, subordinates, peers, and most importantly, clients or customers (Yuksel-Sahin, 2008).

Communication plays an important role in the teaching and learning process as knowledge is transferred through it(Sanders \& Wiseman, 1990). Communication is the life blood of schools as it links individuals in the organisation. The meaning between the intended and the received message, if distorted because of poor communication skills, may cause problems even for the best teachers (Lunenburg \& Ornstein 1996). Communication skills can be described as the essential key to effective and successful teaching.

This is supported by West and Cannon (1988) and Griffin, Dettmer, Thurston and Dyck (1996), who view communication as among the most important skills for educators to possess. This is because effective classroom communication ensures that teaching and learning take place. Therefore, during lessons, students will benefit from the teachers' good verbal communication skills (Ismail \& Idris, 2009). Teachers and students can become frustrated when there is a breakdown in communication. The negative impact would be that the students may begin to play truant by skipping uninspiring lessons and in the classroom, they would become a problem to the teachers and other students. Teachers too would feel the pressure when the students lose interest in their lessons and start to lose concentration in class. Atan (1988) forwards three main aspects that contribute to quality teaching: teachers' personality, knowledge, and communication skills.

Communication skills of teachers are not only essential for teaching but also for collaborating with other teachers. According to Berry, Johnson, and Montgomery (2005), teachers need good communication skills to collaborate with each other to improve teaching skills, and this can be achieved by sharing information. Limited communication skills prevent teachers from coming to a consensus on matters concerning the students (Schmoker, 1999). Thus, modern teaching involves a collaborative teaching style, peer tutoring, and many more approaches which require the use of a lot of communication skills among the teachers.

\subsubsection{Verbal Drivers}

Verbal communication skills are divided into five drivers for this study. Each driver is important as it represents the reason why teachers' communicate. The communication drivers in this study include interpersonal skills, verbal linguistic skills, motivation, altruism, and self-regulation.

It could be said that verbal linguistic intelligence plays a major role in communication. It has been defined as sensitivity to spoken and written language, and the ability to learn languages and to use language to attain goals (Gardner, 2011). Gardner adds that this intelligence includes the ability to effectively use language to express oneself rhetorically or poetically. He also says linguistically intelligent people tend to be more skilled in explaining and speaking. These are the kinds of skills that are vital for teachers, especially language teachers, to have. Generally, verbal-linguistic intelligence is considered by Gardner (1993) as the most widely and most democratically shared skill across the human species.

TESL TPs are in a profession which requires higher interpersonal intelligence. This is because their jobs require them to deal with many different groups of people, who, at any given time, may have different emotions, intentions, or needs. Today, teacher-centered teaching has evolved into learner-centered teaching. This provides an opportunity for cooperative language learning, which is in the domain of interpersonal intelligence (Chen \& Gardner, 2005).

In the area of second language (L2) learning, it has always been recognised that motivation is a pertinent factor in determining the success of L2 learners as it is recognised as a driving force in achievement (Cheng \& Dörnyei, 2007). 
Motivation can be classified as intrinsic (internal) or extrinsic (external). This study is concerned with the extrinsic factor: teachers' ability to motivate students through communication.

Putting other people's welfare before our own, without any selfish motive, is an act of altruism. Wasko and Faraj (2000) identify altruism as the intention to help others. For Somashekhar, Pundhir, and Saxena (2011), altruism is actually an intentional behaviour to help others without expecting any material gains or recognition in return. Costello (2001) says that altruism is manifested in the action done and is not just a felt sense. It is expected of teachers to portray and communicate this virtue. In this study, altruism has been included as a driver to determine whether teachers employ this verbal communication skill when interacting with different categories of people.

Personal, behavioural and environmental processes have been identified by Bandura (1986) as the three main elements which affect an individuals' self-regulation. Bandura further elaborated that individual knowledge, meta-cognition, and postulated aims were part of the personal process of self-regulation. According to him, behavioural process includes self-observation, self-judgement, and self-reaction. Environmental processes include verbal persuasion and modelling. All these elements can be connected to the teacher's self-regulation. A concrete example of exercising self-regulation is when teachers consciously seek to know whether students are able to understand a given lesson before attempting to start another fresh topic. It is clear that teachers today are expected to play multiple roles within and outside of the school environment.

\subsection{Personality Traits}

There is a considerable body of research which indicates that individual differences such as personality traits play a significant role in the learning and teaching process. For teachers, personality traits can mediate the relationship between students' behaviour and the teachers' approach towards the students (Teven, 2007). Therefore, it is deemed essential for teachers to incorporate the consideration of unique aspects of students' learning into their teaching and try to facilitate the process of learning based on the styles and modes by which learners learn more easily and effectively (Tevan, 2007). In one of the few studies investigating personality and its relation to teaching, distinguished teachers were seen to differ from typical teachers in their tendency to be more optimistic, active, imaginative and sensitive (Rushton, Morgan, \& Richard, 2007). Wubbels and Levy (1991) support this view that there is a strong relationship between teachers' affective traits and learners' emotional development.

A well-used measure of personality traits is the Big Five Inventory (BFI), which consists of 44 items devised by John, Donahue, and Kentle in 1991. It defines personality traits in terms of five broad elements, namely Openness, Conscientiousness, Extraversion, Agreeableness, and Neuroticism. The BFI uses short phrases to elicit information on the 'Big Five' traits. Although the phrases are short, they do not jeopardise the content that taps information on the construct properties therein (Benet-Martinez \& John, 1998). As a point of elaboration, teachers with openness as a dominant personality trait are creative and have intellectual curiosity and are aware of other people's feelings. Conscientious teachers have the tendency for self-discipline, to act dutifully and aim for achievement against measures or outside expectations. Teachers who are extroverts enjoy being with people and are often perceived as being full of energy. A person who is generally considerate, friendly, generous, helpful, and willing to compromise his or her interests for the benefit of others comes under the umbrella of agreeableness. Finally, neuroticism, is, however, characterised by negative emotions like anger, anxiety, or depression.

Outstanding teachers may portray a distinct personality profile (Ripski, LoCasale-Crouch, \& Decker, 2011) in order to ease the teaching and learning process, especially when interacting with students who have communication and emotional issues. Research within classrooms indicate that the interactions teachers share with students in the classroom directly contribute to students' success (Hamre \& Pianta, 2005).

\section{Methodology}

\subsection{Instrumentation}

This study adopts a quantitative approach in its research design in which the researcher looks at the pending issue raised in the research question and explains why something happens, which may require an explanation on how one variable affects the other (Creswell, 2012). The study employs questionnaires as an instrument to gather information, namely the communication skills and personality traits questionnaires. The inventory measures the Big Five personality traits of the teacher trainees through the use of 44 items which includes openness, agreeableness, conscientiousness, extraversion, and neuroticism as the domains. On the other hand, communication skills are measured through the use of the Communication Skills Questionnaire (focusing on the use of English), which was adapted from a PhD thesis by WanGould (2010). The questionnaire was sectionalised into five different communication drivers: altruism, interpersonal intelligence, motivation, verbal linguistic intelligence, and self-regulation. Both the questionnaires used a five-point Likert scale as a measurement, ranging from 1 (disagree strongly) to 5 (agree strongly). The communication skills questionnaire was divided into two sections, with the first section eliciting the TPs' background information. The second section investigated the TPs' self-perception of their level of verbal communication skills.

Necessary changes were made to the questionnaire after a pilot test was conducted. Following feedback from the respondents, the font size was increased from 10 to 12 to help participants read the questionnaires clearly. The time allocated was also increased to allow the participants to adequately complete the questionnaire. The original questionnaire was designed for event planners and as such the choice of words needed to be changed as follows: "I have close working relationships with my customers and team members" was changed to "I have close working relationships with my students and colleagues". 
A total of 27 items were constructed in the questionnaire to determine the five communication drivers. Each communication driver was evaluated by a number of items. Each driver was deemed to have equal importance to represent the reason as to why teachers communicate. Teachers communicate for various reasons and with various groups of interlocutors. However, the reasons selected for this study are closely related to the teaching and learning environment.

\subsection{Data Collection}

The research was conducted in four Malaysian teacher training institutes. Consent was obtained from the relevant parties, such as the Ministry of Education Malaysia which is the governing body of the teacher training institutes and also from the heads of the individual institutes. The researcher personally administered the questionnaires to the participants. First, the communication skills questionnaire was administered to all the 277 students in the four teacher training institutes. The TPs were given 30 minutes to complete the communication skills questionnaire; however, most of the participants completed the questionnaire in about 20 minutes. Once the communication skills questionnaire was collected, the personality traits questionnaire was distributed to the TPs. The TPs were also given 30 minutes to answer, but they took less than 20 minutes to complete the questionnaire.

\subsection{Participants}

The 277 respondents in this study were third year TESL trainee practitioner (TP) undergraduates. These TPs were considered suitable for this study as they had been exposed to the school environment in their various practicum training programmes and they had covered all the major courses in their TESL programmes. Thus, the participants were aware of the school scenarios and were also theoretically equipped to teach the English language in schools.

\subsection{Personality Traits Dominance Steps}

The following calculation method was used to determine TPs' dominant personality traits.

Step 1- TPs' responses from the questionnaire were summated according to the traits in SPSS.

Step 2- The summated scores were transferred to Excel.

Step 3- The summated score from each trait was divided according to the number of items in each trait to obtain the average score for each respondent.

Step 4- The maximum average score for each trait and respondent was identified through the "MAX" command. The highest average score among the traits for each respondent was identified through "MATCH" command.

Step 5- A frequency analysis was then carried out to determine the dominant personality trait and its percentage.

Steps one to five analysed the dominant personality traits of the TPs. The aggregated scores were summed up and the highest average was identified, which determined the dominant personality of the TPs. Two types of statistical tools were combined to analyse the data. First, Statistical Package for the Social Sciences (SPSS) version 21 (IBM Corp, 2012) was used to analyse the data on the personality traits. Microsoft Excel (2007) was used to calculate the dominant personality traits of the TPs. The combination of both the tools was to facilitate the analysis effectively as the Excel (2007) programme was better managed by the researcher.

\section{Results}

This section answers the above research question and also addresses the hypotheses. A total of five tables are presented together with this discussion. TPs' performance in the verbal drivers are first presented and discussed in this section. This will help readers to obtain an overview of the comparative dominance of the verbal drivers among the participants. In the verbal communication questionnaire, a total of 27 questions were asked.

\subsection{Descriptive Statistics of TPs' Verbal Communication Skills}

The table below shows TPs' self-perception of their verbal communication skills in English. The mean results indicate the different levels of TPs' strength in the skills evaluated.

Table 1. TPs' Self Perception (TPSP) of their Verbal Communication Skills

\begin{tabular}{lcc}
\hline Verbal Drivers & TPSP Mean & Std. Deviation \\
\hline Interpersonal Intelligence & 3.83 & 0.52 \\
\hline Motivation & 3.79 & 0.53 \\
\hline Verbal Linguistic Intelligence & 3.73 & 0.59 \\
\hline Altruism & 3.67 & 0.51 \\
\hline Self-Regulation & 3.59 & 0.51 \\
\hline
\end{tabular}

TPSP - Trainee Practitioners Self Perception

From Table 1, it is evident that the difference between the mean scores is very minimal for all the components. Mean scores provide an avenue for comparison as computed and tabulated in Table 1. The maximum average mean score is five for each of the drivers. It can be observed that the mean scores are quite high as they are close to a score of four. 
Thus, the skills are perceived to be more than satisfactory as a mean score of four is considered to be relatively high and a score of five would show the attainment of the highest level.

From the table, the highest mean can be seen in interpersonal intelligence. This indicates that most of the TPs were helpful, friendly, and understanding (Maulana, Opdenakker, den Brok \& Bosker, 2011). Numerous studies have also found that teachers rated themselves high on interpersonal communication such as providing support to students and encouraging students to be involved, which is equivalent to motivating them (Fraser, 1982, 1986; Wubbels, Brekelmans,\& Hooymayers, 1992). The lowest mean can be seen in self-regulation. Though this has the lowest mean score it is still satisfactory. The success of TPs is very much influenced by their self-regulation strategies (Hwang \& Vrongistinos, 2002).

The standard deviations in Table 1 do not show much variation. This shows that the answers did not deviate much. However, only verbal linguistics shows a slightly higher standard deviation at 0.59 , which could mean that this construct is more varied among the TPs.

Table 2. TPs' Perception of the Various Properties of Verbal Communication Skills

\begin{tabular}{lc}
\hline & TPPSVC \\
\hline Mean & 101.03 \\
\hline Median & 101.00 \\
\hline Std. Deviation & 12.54 \\
\hline Skewness & -0.25 \\
\hline Kurtosis & 0.28 \\
\hline Minimum & 63 \\
\hline Maximum & 132 \\
\hline Number of items & 27 \\
\hline
\end{tabular}

TPPSVCS - TPs' Perception of Self Verbal Communication Skills

Table 2 presents data describing the TPs' perception of self-verbal communication skills (TPPSVCS). The figures provided are combinations of the five drivers. The table displays a composite score for all of the communication variables. Twenty-seven items were used to measure these variables. The mean value of 101.03 and median of 101.00 are almost the same. The standard deviation is 12.54 which indicate a varied distribution in the responses of the respondents.

In general, the skewness is close to "0", which produces a normal bell shaped curve. The kurtosis is also close to "0" which indicates a normal curve. This generally implies that the data is normally distributed and we can proceed with inferential statistics rather than non-parametric statistics.

4.2 Descriptive Statistics of TPs' Personality Traits

Table 3. TPs' Self Perception (TPSP) of their Personality Traits

\begin{tabular}{llllllll}
\hline Personality Traits & Mean & Median & Std. Deviation & Skewness & Kurtosis & Min & Max \\
\hline Agreeableness & 33.74 & 34 & 4.01 & -0.07 & -0.10 & 24 & 44 \\
\hline Extraversion & 26.45 & 26 & 4.53 & 0.25 & -0.04 & 14 & 40 \\
\hline Conscientiousness & 28.57 & 29 & 4.46 & 0.09 & 0.27 & 15 & 42 \\
\hline Openness & 35.28 & 35 & 4.28 & 0.04 & -0.25 & 24 & 49 \\
\hline Neuroticism & 24.18 & 24 & 5.24 & -0.07 & 0.04 & 09 & 40
\end{tabular}

No. of items x 5 marks $=$ Max Score

Agreeableness : $\quad 9$ items $\times 5$ marks $=45$ marks

Extraversion $\quad: \quad 8$ items $\times 5$ marks $=40$ marks

Conscientiousness : $\quad 9$ items $\times 5$ marks $=45$ marks

Openness $\quad: \quad 10$ items $\times 5$ marks $=50$ marks

Neuroticism $\quad: \quad 8$ items $\times 5$ marks $=40$ marks

The next set of data was obtained from the personality traits questionnaire. Table 3 provides descriptive statistics for the traits analysed in the study. Descriptive statistics are used to describe the basic features of the data in a study. They provide simple summaries about the sample and the measures (William, 2006).

The table establishes the normality distribution of data. The maximum score for each trait is shown below. As can be seen, the maximum score depends on the number of questions in each variable. The minimum (min) and maximum (max) scores in the Table 3 indicate the scores obtained by the participants for each trait. The maximum scores obtained in each trait are similar or close to the maximum scores possible. This indicates that at least one or more participants obtained the projected maximum score. The mean and median are similar, which indicates that there are no extreme results. 
The standard deviation shows the behaviour of the responses. The biggest variation of responses comes from neuroticism. This indicates that the TPs' responses differ from each other. The skewness result was very close to " 0 ", which indicates minimal skewness. The kurtosis shows results close to " 0 ". This means that the distribution produces fewer and less extreme outliers.

Table 4 illustrates the dominant personality traits of the respondents. Costa and McCrae (1995) found that personality trait composition is blemished by the fact that the domains themselves are not mutually exclusive as when some traits appear within two or more domains of the personality traits. A person may have all the traits in him, but one of the traits $\mathrm{m}$ as the dominant personality trait. (?) This means that TPs have specific personalities which are projected as more pronounced in comparison with the rest. This is because every TP has all the personality traits, but one of the traits is dominant or stronger than the other.

Table 4. TESL TPs' Personality Trait Frequency

\begin{tabular}{lcc}
\hline Personality Traits & No of Respondents & Percentage \\
\hline Agreeableness & 143 & 51 \\
\hline Openness & 52 & 19 \\
\hline Extraversion & 37 & 13 \\
\hline Neuroticism & 35 & 13 \\
\hline Conscientiousness & 10 & 4 \\
\hline
\end{tabular}

One hundred and forty-three respondents (51\%) showed that they have agreeableness as their most dominant personality trait. This may be due to influence of culture where they are always taught to give in and be humble, which fits the personality domain of agreeableness. Kosnin and Lee (2008) also found in their study on secondary school teachers that agreeableness was the dominant personality trait in most of the teachers' and neuroticism the least. On the other hand, only $4 \%$ of the respondents were found to have conscientiousness as their dominant personality trait, which had the lowest number of respondents with this personality. Self-discipline and to act dutifully and aim for achievement against measures or outside expectations is a big responsibility for anyone. Fifty-two respondents (19\%) out of the 277 respondents illustrated openness as their main personality trait, which was the second highest trait. Although openness is found to be the second highest personality trait in this study, a study on prospective teachers' personalities in Punjab, Pakistan by Arief, Rashid, Tahira and Akhter (2012) found that out of the 100 prospective teachers, openness was found to be the dominant personality trait. Extraversion was found in 37 respondents (13\%) showing it as their main personality trait. Being sociable is one of the main domains of this personality. As most of the respondents are Malaysian females they are bound by Asian culture. Thus, it's safe to say that the score is acceptable. Thirty-five respondents $(13 \%)$ showed themselves as having the trait of neuroticism, which is a negative personality trait. Watson, Clark, and Harkness (1994) opined that those who exhibit high traits of neuroticism are inclined towards expressing more negative emotions and exhibiting emotional instability and stress reaction. Thus, they become more susceptible to burn-out, which increases the risk of developing psychopathology.

\subsection{Relationship between TPs' Big Five and their Verbal Communication Skills}

Table 5 presents the results of the Chi square analysis, which is a univariate analysis, to show the relationship between the TPs' personality traits and their verbal communication skills.

Table 5. TPs' Personality Traits and their Relation to Verbal Communication Skills

\begin{tabular}{|c|c|c|c|c|c|c|}
\hline & Value & Df & \multicolumn{2}{|c|}{ Sig. (2-tailed) } & Value & Approx. Sig. \\
\hline \multicolumn{7}{|l|}{ Agreeableness } \\
\hline Pearson Chi-Square & 1195.67 & 1200 & 0.53 & Phi & 2.08 & 0.53 \\
\hline Likelihood Ratio & 673.83 & 1200 & 1 & Cramer's V & 0.46 & 0.53 \\
\hline \multicolumn{7}{|l|}{ Extraversion } \\
\hline Pearson Chi-Square & 1332.36 & 1380 & 0.82 & Phi & 2.19 & 0.82 \\
\hline Likelihood Ratio & 750.78 & 1380 & 1 & Cramer's V & 0.46 & 0.82 \\
\hline \multicolumn{7}{|l|}{ Conscientiousness } \\
\hline Pearson Chi-Square & 1404.36 & 1440 & 0.74 & Phi & 2.25 & 0.74 \\
\hline Likelihood Ratio & 708.57 & 1440 & 1 & Cramer's V & 0.46 & 0.74 \\
\hline \multicolumn{7}{|l|}{ Openness } \\
\hline Pearson Chi-Square & 1541.16 & 1380 & 0.01 & Phi & 2.36 & 0.00 \\
\hline Likelihood Ratio & 738.53 & 1380 & 1 & Cramer's V & 0.49 & 0.00 \\
\hline \multicolumn{7}{|l|}{ Neuroticism } \\
\hline Pearson Chi-Square & 1485.21 & 1620 & 0.99 & Phi & 2.32 & 0.99 \\
\hline Likelihood Ratio & 772.55 & 1620 & 1 & Cramer's V & 0.45 & 0.99 \\
\hline
\end{tabular}

Number of Valid Cases $=277$ 
Table 5 illustrates the association between the TPs' verbal communication and personality traits. From the table, the only personality trait that shows a significant association with communication skills is openness, which is not the most dominant trait. In a study by Zhang (2007) on the correlation of Chinese teachers' personality traits and their teaching it was found that only openness was positively correlated. The significance value is 0.01 , which is lower than 0.05 . Openness implies that the students regard themselves as imaginative, intelligent, original, insightful, curious, and sophisticated, among others traits. TPs with openness as their dominant personality trait tend to communicate verbally more than those with other dominant personality traits. The other personality traits were not significantly associated with the TPs' verbal communication skills. Job (2004) found in his study that agreeableness, neuroticism and openness were negatively correlated with teachers' effectiveness which included teachers' communication skills. Buela and Mamman (2015), however, differed on this issue as in their study they found agreeableness to have the highest correlation. In other words, this could imply that TPs with agreeableness as their most dominant personality trait may be more accepting, but it does not manifest in the greater use of the English language in communicating. Hence, the hypothesis on the positive relationship between openness and verbal communication is accepted. As for the other hypotheses, the null is accepted and the alternate is rejected.

\section{Discussion and Conclusion}

As for the verbal communication drivers, they all had mean scores of above 3.5, which are all reasonably high. The highest self-perception score for the verbal communication drivers can be seen in interpersonal intelligence (3.83) and the lowest score in self-regulation (3.59). The mean scores are similar to each other, and this may indicate that the TPs generally regarded themselves as having a good command of verbal communication skills. There is also a possibility that the drivers are not mutually exclusive, and they are intertwined to a certain extent. Though each driver is defined exclusively, the drivers do converge to a certain degree. However, as teachers, the scores indicate that there is still room for improvement. They should strive to be excellent communicators with scores of 4.0 and above to indicate a marked distinction in their profession insofar as the use of communication skills is concerned. As the literature implies, teachers must excel in their communication skills as this is paramount in effective teaching. Thus, TESL teachers should set their goals to a higher level in their ability to communicate in the English language.

The results of the univariate analysis also show that out of the five personality traits, only one of the traits showed a significant value in its relationship to TPs' verbal communication, which is openness (rated only by $19 \%$ as being dominant). If the stand is taken that communication skills are core skills in successful teaching, then the TPs would want to pay attention to this personality traits by exploiting to the fullest its relation to the ability to communicate. In other words, openness needs to be more dominant as a personality trait. While agreeableness is highly valued, it would also make sense to explore how this could further enhance the use of communication skills. Perhaps there is a path that could be explored to investigate how the sub skills of agreeableness could be functionally and consciously translated into the use of the English language to convey the trait of agreeableness. This suggestion could also apply to the other traits under investigation as a manner of enhancing the relationship between personality traits and communication skills.

Generally, the TPs rated themselves as having a reasonable level of awareness of their personality traits and the questionnaire could be an eye opener for self-evaluation and reflection. Also, they could explore more about the constructs in a conscious effort to improve on the traits so that students and teachers benefit from the exercise. Personality traits may be viewed as a composite behaviour. Though each respondent may have a dominant personality, Costa and McRae (1995) found that personality traits are not mutually exclusive, which means the traits may influence one another.

The teaching profession and in particular, teachers, are always under scrutiny about their teaching skills which include their knowledge, communication skills and their personalities. This could put them under a lot of pressure. Constant improvement is necessarily the clarion call if teaching is to be effective. Improvements to the teaching profession can only take place by the teachers' own initiative and government initiative. TPs need to acquire and possess good communication skills and develop or enhance their personality traits positively in order to communicate effectively. This study has attempted to investigate the relationship between personality traits and communication skills. The study also illustrates that there are further innovations in education to be explored. A change in mindset is needed so that teachers will be able to further develop their repertoire of skills.

The study has provided an opportunity for teachers to assess their personality traits and communication skills. More importantly, it opens an avenue for discussing the relationship between personality traits and communication skills. With this awareness, the teaching profession can definitely be enhanced with the addition of relevant knowledge towards the ultimate aim of raising the standard of teaching and learning. Currently, the Ministry of Education in Malaysia is embarking on an ambitious change and so no stone should be left unturned in the quest for positive and meaningful change.

\section{References}

Arif, M. I., Rashid, A., Tahira, S. S., \& Akhter, M. (2012). Personality and teaching: an investigation into prospective teachers' personality. International Journal of Humanities and Social Science, 2(17), 161-171.

Atan Long. (1988). Psikologi Pendidikan. Kuala Lumpur, Malaysia: Dewan Bahasa dan Pustaka. 
Bandura, A. (1986). Social foundations of thought and action: A social cognitive theory. Englewood Cliffs, NJ: Prentice-Hall, Inc.

Barrick, M. R., \& Mount, M. K. (1991). The Big Five personality dimensions and job performance: A meta-analysis. Personnel Psychology, 44 (1), 1-26.

Benet-Martinez, V., \& John, O. P. (1998). Los Cinco Grandes across cultures and ethnic groups: Multitrait-multimethod analyses of the Big Five in Spanish and English. Journal of Personality and Social Psychology, 75(3), 729-750.

Berry, B., Johnson, D., \& Montgomery, D. (2005). The power of teacher leadership. Educational Leadership, 62(5), 5660.

Buela, S., \& Mamman Joseph, C. (2015). Relationship between Personality and Teacher Effectiveness of High School Teachers. The International Journal of Indian Psychology, 3(1), 57-70

Chu, C. L. (2003). A study of the relationship between personality traits and teaching effectiveness of teachers in reward and non-reward kindergartens in Taiwan. Unpublished doctoral dissertation, Spalding University: Louisville, KY

Chen, J., \& Gardner, H. (2005). Assessment based on multiple-intelligences theory. In D. P. Flanagan (Ed.), Contemporary intellectual assessment: Theories, tests, and issues (pp. 77-102). New York : Guilford Press.

Cheng, H. F., \& Dörnyei, Z. (2007). The use of motivational strategies in language instruction: The case of EFL teaching in Taiwan. International Journal of Innovation in Language Learning and Teaching, 1(1), 153-174.

Cloninger, C. R. (2000). A practical way to diagnosis personality disorder: A proposal. Journal of Personality Disorders, 14(2), 99-108.

Costa Jr, P. T., \& McCrae, R. R. (1995). Domains and facets: Hierarchical personality assessment using the Revised NEO Personality Inventory. Journal of Personality Assessment, 64(1), 21-50.

Costello, C. (2001). Altruism: Selfish or selfless? Retrieved from http://serendip.brynmawr.edu/bb/neuro/neuro01/web2/Costello.html

Creswell, J. W. (2012). Qualitative inquiry and research design: Choosing among five approaches. California: Sage.

Davis. K. L. (1995). The teaching interview: Principals' perceptions of teacher traits and the link to student achievement (Unpublished doctoral thesis). Capella University: Minneapolis, Minnesota.

Fatemi, M. A., Ganjal, R., \& Kafi, Z. (2016). EFL Teachers' Personality Type and Their Effectiveness in Teaching: Investigating the Relationship. International Journal of Educational Investigations, 3(1), 166-177.

Fraser, B. J. (1982). Differences between student and teacher perceptions of actual and preferred classroom learning environment. Educational Evaluation and Policy Analysis, 4(4), 511-519.

Fraser, B. J. (1986).Classroom environment. London: Croom Helm

Gardner, J. (1993). On leadership. New York: Simon and Schuster.

Gardner, H. (2011). Frames of mind: The theory of multiple intelligences. New York: Basic Books.

Gewertz, C. (2007). Soft skills in big demand. Education Week, 26(40), 25-27.

Griffin, C. C., Dettmer, P., Thurston, L. P., \& Dyck, N. (1995). Consultation, collaboration, and teamwork for students with special needs. Boston, MD: Allyn and Bacon.

Hamachek, D. E. (1985). The self development and ego growth: Conceptual analysis and implications for counsellors. Journal of Counseling \& Development, 64(2), 136-142.

Hamre, B. K., \& Pianta, R. C. (2004). Self-reported depression in nonfamilial caregivers: Prevalence and associations with caregiver behavior in child-care settings. Early Childhood Research Quarterly, 19(2), 297-318.

Henson, R. K. , \& Chambers, S. M. (2002). Personality type as a predictor of teaching efficacy and classroom control in emergency certification teachers. Education, 124(2), 261-282.

Hairi, F., Nazuir, M., \& Razzaly, W. (2011). Employers' perception on soft skills of graduates: A study of Intel elite soft skill training. Retrieved from http://eprints.uthm.edu.my/2191/

Howes, C., Burchinal, M., Pianta, R., Bryant, D., Early, D., Clifford, R., \& Barbarin, O. (2008). Ready to learn? Children's pre-academic achievement in pre-kindergarten programs. Early Childhood Research Quarterly, 23(1), 2750 .

Hwang, Y. S., \& Vrongistinos, K. (2002). Elementary in-service teachers' self-regulated learning strategies related to their academic achievements. Journal of Instructional Psychology, 29(3), 147-154.

IBM Corp. (2012) IBM SPSS Statistics for Windows, Version 21.0. Armonk, NY: IBM Corp.

Ismail, N., \& Idris, K. N. (2009). The effects of classroom communication on students' academic performance at the International Islamic University Malaysia (IIUM). Unitar E-Journal, 5(1), 37-49.

Job A. P. (2004). The Relationship Between Personality, Occupation and Student Evaluations of Teaching Effectiveness of Adjunct Faculty Vol. 65 Doctoral dissertation, Portland State University; Portland: USA. 
Joinson, A. N. (2004). Self-esteem, interpersonal risk, and preference for e-mail to face-to-face communication. CyberPsychology \& Behavior, 7(4), 472-478.

Kosnin, A. M., \& Lee, T. S. (2008). Pengaruh personaliti terhadap kepuasan kerja dan stres kerja guru. Sains Humanika, 48(1), 33-47.

Lunenburg, F. C. \& Ornstein, A. C. (1996). Educational administration: Concepts and Practices. CA: Wadsworth Publishing Co.

Maulana, R., Opdenakker, M. C., den Brok, P., \& Bosker, R. (2011). Teacher-student interpersonal relationships in Indonesia: Profiles and importance to student motivation. Asia Pacific Journal of Education, 31(01), 33-49.

Mason, G., Williams, G., \& Cranmer, S. (2009). Employability skills initiatives in higher education: What effects do they have on graduate labour market outcomes? Education Economics, 17(1), 1-30.

Meikeng, Y (2015, November 15). Poor English a major handicap. The Star Newspaper. Retrieved from http://www.thestar.com.my/news/nation/2015/11/15/poor-english-a-major-handicap-its-not-just-young-doctors-

workers-in-various-sectors-too-have-a-weak/

Norazila, A. (2010). A study of soft skills among bank staff in Kajang. Unpublished doctoral dissertation, Universiti Utara Malaysia, Kedah, Malaysia.

Ripski, M. B., LoCasale-Crouch, J., \& Decker, L. (2011). Pre-service teachers: Dispositional traits, emotional states, and quality of teacher-student interactions. Teacher Education Quarterly, 38(2), 77-96.

Rushton, S., Morgan, J., \& Richard, M. (2007). Teacher's Myers-Briggs personality profiles: Identifying effective teacher personality traits. Teaching and Teacher Education, 23(4), 432-441.

Sanders, J. A., \& Wiseman, R. L. (1990). The effects of verbal and nonverbal teacher immediacy on perceived cognitive, affective, and behavioral learning in the multicultural classroom. Communication Education, 39(4), 341-353.

Saunders, P. L., \& Chester, A. (2008). Shyness and the internet: Social problem or panacea? Computers in human behaviour, 24(6), 2649-2658.

Schmoker, M. J. (1999). Results: The key to continuous school improvement. AZ: ASCD.

Sim, O. M. (2016, March 13). Making jobless grads employable. The Star Newspaper. Retrieved from http://www.thestar.com.my/news/education/2016/03/13/making-jobless-grads-employable/

Somashekhar, D. R., Pundhir, S., \& Saxena, A. (2011). Towards more effective relations among employees: A study of altruism among teachers in India. International Journal of Management, 28(3), 939-944.

Teven, J. J. (2007). Teacher caring and classroom behaviour: Relationships with student affect and perceptions of teacher competence and trustworthiness. Communication Quarterly, 55(4), 433-450.

Wan-Gould, C. (2010). A correlational study of event planners' personality traits, soft skills competency, and selfleadership Doctoral dissertation, University Of Phoenix, Tempe, Arizona, USA.

Wasko, M. M., \& Faraj, S. (2000). "It is what one does": Why people participate and help others in electronic communities of practice. The Journal of Strategic Information Systems, 9(2), 155-173.

Watson, D., Clark, L. A., \& Harkness, A. R. (1994). Structures of personality and their relevance to psychopathology. Journal of Abnormal Ppsychology, 103(1), 18-31.

West, J. F., \& Cannon, G. S. (1988). Essential collaborative consultation competencies for regular and special educators. Journal of Learning Disabilities, 21(1), 56-63.

William M.K.T (2006). Research Methods Knowledge Base. Retrieved from http://www.socialresearchmethods.net/kb/statdesc.php.

Wubbels, T., \& Levy, J. (1991). A comparison of interpersonal behavior of Dutch and American teachers. International Journal of Intercultural Relations, 15(1), 1-18.

Wubbels, T., Brekelmans, M., \& Hooymayers, H. P. (1992).Interpersonal teacher behavior in the classroom. In B. J. Fraser, \& H. J. Walberg (Eds.),Educational environments:Evaluation, antecedents and consequences(pp. 141-160). Oxford: Pergamon.

Yuksel-Sahin, F. (2008). Communication skill levels in Turkish prospective teachers. Social Behaviour and Personality: An International Journal, 36(9), 1283-1294.

Zhang, L. F. (2007). Do personality traits make a difference in teaching styles among Chinese high school teachers? Personality and Individual Differences, 43(4), 669-679. 